\title{
Diagnostic performance of various familial hypercholesterolaemia diagnostic criteria compared to Dutch lipid clinic criteria in an Asian population
}

Suraya Abdul-Razak ${ }^{1,3}$, Radzi Rahmat ${ }^{2}$, Alicezah Mohd Kasim,2, Thuhairah Abdul Rahman ${ }^{1,2}$, Suhaila Muid ${ }^{1,2}$, Nadzimah Mohd Nasir ${ }^{2}$, Zubin Ibrahim ${ }^{1,4}$, Sazzli Kasim ${ }^{1,4}$, Zaliha Ismail ${ }^{1,5}$, Rohana Abdul Ghani, ${ }^{1,6}$, Abdul Rais Sanusi ${ }^{7}$, Azhari Rosman ${ }^{7}$ and Hapizah Nawawi ${ }^{1,2^{*}}$ (D)

\begin{abstract}
Background: Familial hypercholesterolaemia (FH) is a genetic disorder with a high risk of developing premature coronary artery disease that should be diagnosed as early as possible. Several clinical diagnostic criteria for FH are available, with the Dutch Lipid Clinic Criteria (DLCC) being widely used. Information regarding diagnostic performances of the other criteria against the DLCC is scarce. We aimed to examine the diagnostic performance of the Simon-Broom (SB) Register criteria, the US Make Early Diagnosis to Prevent Early Deaths (US MEDPED) and the Japanese FH Management Criteria (JFHMC) compared to the DLCC.

Methods: Seven hundered fifty five individuals from specialist clinics and community health screenings with LDL-c level $\geq 4.0 \mathrm{mmol} / \mathrm{L}$ were selected and diagnosed as FH using the DLCC, the SB Register criteria, the US MEDPED and the JFHMC. The sensitivity, specificity, efficiency, positive and negative predictive values of individuals screened with the SB register criteria, US MEDPED and JFHMC were assessed against the DLCC.

Results: We found the SB register criteria identified more individuals with FH compared to the US MEDPED and the JFHMC (212 vs. 105 vs. 195; $p$ < 0.001) when assessed against the DLCC. The SB Register criteria, the US MEDPED and the JFHMC had low sensitivity ( $51.1 \%$ vs. $25.3 \%$ vs. $47.0 \%$ respectively). The SB Register criteria showed better diagnostic performance than the other criteria with $98.8 \%$ specificity, $28.6 \%$ efficiency value, $98.1 \%$ and $62.3 \%$ for positive and negative predictive values respectively.
\end{abstract}

Conclusion: The SB Register criteria appears to be more useful in identifying positive cases leading to genetic testing compared to the JFHMC and US MEDPED in this Asian population. However, further research looking into a suitable diagnosis criterion with high likelihood of positive genetic findings is required in the Asian population including in Malaysia.

Keywords: Familial Hypercholesterolaemia, Simon Broome, Dutch Lipid Clinic Criteria, US Make Early Diagnosis to Prevent Early Deaths, Japanese FH Management Guideline Criteria

\footnotetext{
* Correspondence: hapizah.nawawi@gmail.com

1 Institute for Pathology, Laboratory and Forensic Medicine (I-PPerForM),

University Teknologi MARA, 47000 Sungai Buloh, Selangor, Malaysia

${ }^{2}$ Pathology Discipline, Faculty of Medicine, University Teknologi MARA, 47000

Sungai Buloh, Selangor, Malaysia

Full list of author information is available at the end of the article
} 


\section{Background}

Familial hypercholesterolaemia $(\mathrm{FH})$ is an autosomal dominant disorder affecting between $1 / 200$ to $1 / 500$ individuals worldwide. The elevated serum cholesterol leads to more than $50 \%$ risk of fatal coronary artery disease in men and women [1]. FH occurs clinically in two forms namely, heterozygous $\mathrm{FH}$ and homozygous $\mathrm{FH}$ [2]. Patients with a mutation in both low-density lipoprotein receptor (LDLR) alleles are more severely affected than patients with a single mutant allele. Heterozygous FH has two to three fold elevations in plasma low-density lipoprotein (LDL-c) and typically begin to develop premature coronary artery disease (CAD) at the age of 30 to 40 years [3, 4]. In contrast, homozygous $\mathrm{FH}$ have six to ten times higher than the normal concentration of plasma LDL-c from birth and often have heart attacks during the first two decades of life $[2,5]$.

In the UK, the National Institute for Health and Care Excellence (NICE) recommends the Simon-Broome Register (SB) Register criteria [6] which includes raised cholesterol levels, family history of premature heart disease and hypercholestrolaemia, clinical characteristics, family history of premature CAD but also included a molecular diagnosis for confirmation of possible $\mathrm{FH}$ (Table 1). The Dutch Lipid Clinic Criteria (DLCC) is widely recommended for the rest of Europe. It is similar to the SB Register criteria but each criterion is given a weightage (Table 2) [7].

Unlike the SB Register or the DLLC, the US Make Early Diagnosis to Prevent Early Deaths (US MEDPED) criteria defined FH based on age-specific and relative's specific criteria for total cholesterol. The serum cholesterol cut-off points used in general populations are higher compared to serum cholesterol cut-off value when they had a first- and second- or third degree relatives with FH (Table 3).

Table 1 Simon Broome Register Group of FH A definite diagnosis of $\mathrm{FH}$ requires:

(a) Total cholesterol level above $7.5 \mathrm{mmol} / \mathrm{L}(290 \mathrm{mg} / \mathrm{dl})$ in adults or a total cholesterol level above $6.7 \mathrm{mmol} / \mathrm{L}(260 \mathrm{mg} / \mathrm{dl})$ for children under 16 OR LDL-c levels above $4.9 \mathrm{mmol} / \mathrm{L}$ (190 mg/dL) in adults (4.0 mmol/L in children) (either pretreatment or highest on treatment) PLUS

(b) tendon xanthomas in patient or relative (parent, child, sibling, grandparent, aunt, uncle) OR

(c) DNA-based evidence of an LDL receptor mutation or familial defective apo B-100

Possible FH is defined as (a) above plus one (d) or (e):

(d) Family history of myocardial infarction before age 50 in grandparent, aunt, uncle or before age 60 in parent, sibling or child.

(e) Family history of raised cholesterol in parent sibling or child, or level above $7.5 \mathrm{mmol} / \mathrm{L}(290 \mathrm{mg} / \mathrm{dl})$ in grandparent, uncle, aunt
The Japanese FH Management Criteria (JFHMC) recently defined $\mathrm{FH}$ into two groups of either homozygous $\mathrm{FH}$ or heterozygous FH. The homozygous FH must feature all of these criteria; serum total cholesterol of $15.5 \mathrm{mmol} / \mathrm{L}$ or more, presence of tendon xanthoma, premature CAD during childhood and a family history of heterozygous $\mathrm{FH}$ among the parents; while heterozygous $\mathrm{FH}$ is defined by LDL-c $\geq 4.7 \mathrm{mmol} / \mathrm{L}$, presence of tendon xanthomas, and family history within the second-degree relatives with $\mathrm{FH}$ or premature CAD (Table 4).

Despite established clinical assessment guidelines, most people with $\mathrm{FH}$ are undiagnosed or only diagnosed after their first coronary event [8]. Treatment with statin is effective in $\mathrm{FH}$ and early treatment delays or prevents the onset of CAD [9-11]. Hence, early identification of affected individuals is vital as treatment could substantially reduce the risk of coronary events. Most European countries diagnose less than $20 \%$ of all estimated cases [8], while in the UK, only $25 \%$ were diagnosed; with the remain undiagnosed until middle age [12]. In the USA, less than $10 \%$ of $\mathrm{FH}$ are formally diagnosed [13]. The readily available clinical guidelines for $\mathrm{FH}$ register have limited utility in case findings in their settings as both the DLCC and the SB Register criteria would require genetic testing. Genetic testing is recommended when a mutation is known within a family but only $10 \%$ to $40 \%$ of those with a clinical diagnosis of $\mathrm{FH}$ would have a mutation [8, 14]. Furthermore, genetic testing alone has become less favourable as a diagnostic criterion as the facility is not widely available and is expensive [14]. Therefore, case detections via personal and family history, physical examinations and other biochemical markers have been used to identify individuals in many countries including Malaysia. Currently, the prevalence of $\mathrm{FH}$ is still unclear in this country and there are no local criteria available to diagnose $\mathrm{FH}$ to be used by health care professionals. It is observed that the DLCC and the SB register criteria have been used invariably to diagnose $\mathrm{FH}$ in this country. However, diagnostic performance of all the criteria in detecting $\mathrm{FH}$ in Asian populations is unknown. This study aimed to examine the diagnostic performance of the SB Register criteria, the US MEDPED and the JFHMC compared to the DLCC. We also aimed to investigate the association between FH subgroup of the SB Register criteria, the US MEDPED and the JFHMC with the DLCC.

\section{Methods}

Study design

This is a cross sectional study involving 755 individuals with LDL-c level of $\geq 4.0 \mathrm{mmol} / \mathrm{L}$ recruited from multiple centres including the institution's specialist primary care, lipids and cardiology clinics; National Heart 
Table 2 Dutch Lipid Clinic network diagnosis of FH

\begin{tabular}{ll}
\hline Criteria & Points \\
\hline Family History & \\
A First degree relative with known premature ( $<55$ years men; & 1 \\
$<60$ years women) coronary disease and vascular disease OR & \\
LDL-c $>95^{\text {th }}$ percentile & 2 \\
B First degree relative with tendon xanthomata and/or & \\
arcuscornealis OR childhood (<18 years) with LDL-c $>95^{\text {th }}$ & \\
percentile & \\
Clinical history & \\
A Patient with premature CAD (men $<55$, women $<60$ years) & 2 \\
B Patient with premature cerebral or PVD (men $<55$, women & 1 \\
$<60$ years) & \\
Physical Examination & 6 \\
A Tendon xanthomas & 4 \\
B Premature arcus & 8 \\
Lab analysis & \\
A LDL - C $>8.5$ mmol/L & \\
B LDL-c 6.5-8.4 mmol/L & 5 \\
C LDL- C 5.0-6.4 mmol/L & 3 \\
D LDL - C 4.0-4.9 mmol/L & 1 \\
Functional & \\
DNA mutations & \\
Definite FH: $>8$ points, Probable FH: 6-8 points, Possible FH: 3-5 & \\
\hline
\end{tabular}

Institute as well as community health screening programmes conducted from January 2011 to January 2015. Sample size was calculated using single proportion formula [15] based on proportion of positive $\mathrm{FH}$ detected using the SB Register criteria [14], US MEDPED [14] and JFHMC [16] considering 95\% confidence interval, the required calculated sample size was 384 . The exclusion criteria were subjects with secondary hypercholesterolaemia such as hypothyroidism, nephrotic syndrome, chronic kidney disease based on CKD EPI guidelines [17] and obstructive liver diseases. Eligible subjects were

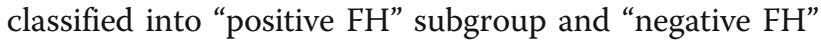
subgroup by the DLCC. Cases were identified as positive $\mathrm{FH}$ when the subjects achieved $\geq 3$ points by the DLCC while subjects were classified as negative $\mathrm{FH}$ when the subjects achieved $<3$ points by the DLCC. Both groups were matched for age, gender, ethnicity, diabetes, hypertension and smoking status. Subsequently, all individuals were regrouped to be defined as "Yes FH" or "No FH"

Table 3 The US MEDPED Criteria

\begin{tabular}{lllll}
\hline Age (year) & 1st degree & 2nd degree & 3rd degree & General population \\
\hline$<20$ & 5.7 & 5.9 & 6.2 & 7.0 \\
$20-29$ & 6.2 & 6.5 & 6.7 & 7.5 \\
$30-39$ & 7.0 & 7.2 & 7.5 & 8.8 \\
$\geq 40$ & 7.5 & 7.8 & 8.0 & 9.3 \\
\hline
\end{tabular}

Table 4 Diagnostic criteria for adult (15 years or older) homozygous FH by the Japanese FH Management Guideline Criteria

Hypercholesterolaemia (serum total cholesterol before treatment: $\geq 15.5 \mathrm{mmol} / \mathrm{L})$

Tendon xanthomata (tendon xanthoma on the dorsal hands, elbows, and knees, or Achilles tendon thickening ${ }^{1}$ ) or nodular xanthoma on the skin

Premature CAD during childhood

Parents' family history of heterozygous FH.

Diagnostic criteria for adult (15 years or older) heterozygous $\mathrm{FH}$ by the Japanese FH Management Guideline Criteria

Hyper- LDL cholesteroalemia (LDL-C before treatment: $\geq 4.7 \mathrm{mmol} / \mathrm{L}$ ) Tendon xanthomata (tendon xanthoma on the dorsal hands, elbows, and knees, or Achilles tendon thickening) or nodular xanthoma on the skin

Family history within the second- degree relatives $\mathrm{FH}$ or premature CAD (men $<55$, women $<60$ years)

${ }^{1}$ Patients with Achilles tendon thickening ( $\geq 9 \mathrm{~mm}$ ) on radiography should be regarded as having xanthoma

by the SB Register criteria, the US MEDPED and by the JFHMC. DLCC Positive FH subjects were then reclassified according to the subgroups of $\mathrm{FH}$ by the SB Register criteria, the US MEDPED and the JFHMC. For patients who were on lipid-lowering treatment at the time of measurement, pre-treatment LDL-c level was used, but if the pre-treatment level was not available, it was predicted using a correction table by Ellis et al. [18], which requires the information of current type of administered statin and its dose. Genetic mutation confirmation was not included in making the diagnosis of positive $\mathrm{FH}$ by the DLCC and SB Register criteria used. Family cascade screening was later performed for positive $\mathrm{FH}$ index cases identified by the DLCC criteria.

\section{Data collection}

Subjects were given information on the study objectives and invited to participate. A standard questionnaire was used to obtain socio-demographic characteristics (age, gender, and ethnicity), lifestyle risk factors (smoking status), personal and family history of CAD. Anthropometric data including height and body weight to determine body mass index (BMI), waist circumference (WC) and blood pressure (BP) were also collected. The blood pressure was measured at least three times at $5 \mathrm{~min}$ apart on the right arm supported at heart level, using Omron automatic digital blood pressure monitor (Omron HEM-757). The average of the last $2 \mathrm{BP}$ readings was used for analysis. Height and weight were measured by trained nursing staff using a balance beam scale with the subjects' shoes removed. BMI was calculated as weight in kilograms divided by the square of height in meters $\left(\mathrm{kg} / \mathrm{m}^{2}\right)$. WC was measured to the nearest $0.5 \mathrm{~cm}$ using a measuring tape midway between the inferior margin of the last rib and the iliac crest in a horizontal plane. Fasting serum and plasma 
samples were collected for the measurement of lipid profile using automated analyzers (Roche, Cobas Integra 400, USA and Centaur XP, Siemens, USA).

\section{Statistical analysis}

All statistical analysis was performed using IBM Statistical Program for Social Science Software (SPSS) ver. 16.0 for Windows. Variables with normal distribution were expressed as mean \pm standard error of mean (SEM). The comparisons of FH detected by the different criteria used to diagnose FH were determined using chisquare test. $P$-values $<0.05$ were considered as significant. Sensitivity, specificity, positive, negative predictive and accuracy values were determined for positive $\mathrm{FH}$ diagnoses as defined by the positive $\mathrm{FH}$ by the DLCC against the SB Register criteria, the US MEDPED and the JHMC definition. Efficiency was defined as the sum of the correct diagnoses (positive and negative by the DLCC criteria) divided by all subjects. Significance level was set at $p$-value of $<0.05$.

\section{Results}

A total of 415 subjects were classified as "positive FH" and 340 subjects as "negative FH" by the DLCC in the study. The baseline characteristics of the subjects in both groups were summarized in Table 5. It was found that the presence of CAD, xanthomas, corneal arcus, total cholesterol (TC) level and LDL-c level were significantly higher in positive $\mathrm{FH}$ group compared to negative FH group $(p<0.001)$.

Table 6 showed the sensitivity and specificity of positive $\mathrm{FH}$ as defined by the SB Register criteria, the US MEDPED and the JFHMC against the DLCC as the reference criteria for diagnosis. The SB Register criteria was able to identify $51.1 \%$ positive $\mathrm{FH}$ out of the total DLCC defined cases. There was a high positive predictive value of $98.8 \%$ with a low efficiency value at $28.6 \%$. The second best diagnostic performance was by the JFHMC with a sensitivity of $47.0 \%$, a positive predictive value of $97.9 \%$ and efficiency value of $26.4 \%$. The US MEDPED was only successful in diagnosing $25.3 \%$ of those diagnosed with FH by the DLCC. The negative predictive value was acceptable at $52.1 \%$. The efficiency value was comparable with the value obtained with the SB Register criteria against the DLCC (26.4\% vs. $28.6 \%$ respectively). It was also noted that from positive $\mathrm{FH}$ cases defined by the DLCC, the SB Register criteria identified the most number of positive FH compared to the

Table 5 Baseline characteristics of subjects with DLCC positive and DLCC negative

\begin{tabular}{|c|c|c|c|}
\hline Parameter & DLCC Positive $n=415$ & DLCC Negative $n=340$ & $P$ value \\
\hline${ }^{\mathrm{b}}$ Age (Years) & $47.5 \pm 0.62$ & $47.2 \pm 0.7$ & Ns \\
\hline \multirow[t]{2}{*}{${ }^{\mathrm{a}}$ Gender } & Male: 52.1 & Male: 44.2 & Ns \\
\hline & Female: 47.9 & Female: 55.8 & \\
\hline \multirow[t]{4}{*}{${ }^{a}$ Ethnicity } & Malay: 75.2 & Malay: 81.5 & Ns \\
\hline & Chinese: 16.1 & Chinese: 10.9 & \\
\hline & Indian: 5.5 & Indian: 3.2 & \\
\hline & Other: 3.2 & Other: 4.4 & \\
\hline${ }^{a}$ Hypertension & 19.6 & 15.7 & Ns \\
\hline${ }^{b} \mathrm{SBP}(\mathrm{mmHg})$ & $126.3 \pm 1.2$ & $125.4 \pm 0.9$ & Ns \\
\hline${ }^{\mathrm{b}} \mathrm{DBP}(\mathrm{mmHg})$ & $74.9 \pm 0.8$ & $75.9 \pm 0.7$ & Ns \\
\hline 'Diabetes & 5.0 & 8.5 & Ns \\
\hline${ }^{b}$ Plasma glucose (mmol/L) & $5.6 \pm 0.2$ & $5.7 \pm 0.2$ & Ns \\
\hline${ }^{\mathrm{a} S}$ Smoking & $\begin{array}{l}\text { Yes: } 14.2 \\
\text { No: } 85.8\end{array}$ & $\begin{array}{l}\text { Yes: } 17 \\
\text { No: } 73\end{array}$ & Ns \\
\hline${ }^{\mathrm{b}} \mathrm{BMI}$ & $26.5 \pm 0.3$ & $26.5 \pm 0.3$ & Ns \\
\hline${ }^{\mathrm{b}} \mathrm{TC}(\mathrm{mmol} / \mathrm{L})$ & $8.0 \pm 0.07$ & $6.5 \pm 0.02$ & * \\
\hline${ }^{\mathrm{b}} \mathrm{TG}(\mathrm{mmol} / \mathrm{L})$ & $2.0 \pm 1.8$ & $1.8 \pm 1.0$ & Ns \\
\hline${ }^{b} \mathrm{LDL}(\mathrm{mmol} / \mathrm{L})$ & $5.8 \pm 0.1$ & $4.4 \pm 0.1$ & * \\
\hline${ }^{\mathrm{b}} \mathrm{HDL}(\mathrm{mmol} / \mathrm{L})$ & $1.3 \pm 0.1$ & $1.4 \pm 0.1$ & Ns \\
\hline${ }^{b} W C$ & $88.6 \pm 1.1$ & $87.2 \pm 0.6$ & Ns \\
\hline aXanthomas & 29.4 & 0.0 & * \\
\hline${ }^{\mathrm{a}} \mathrm{CA}$ & 20.2 & 0.5 & * \\
\hline${ }^{\mathrm{a}} \mathrm{CAD}$ & 16.1 & 0.0 & * \\
\hline
\end{tabular}


Table 6 Sensitivity, specificity, positive predictive value and negative predictive value for positive FH as defined by the SB, US MEDPED and JFHMC definitions against the DLCC definition

\begin{tabular}{|c|c|c|c|c|c|c|c|c|c|}
\hline \multirow[t]{2}{*}{ Definitions } & \multicolumn{9}{|l|}{ DLCC } \\
\hline & Yes FH & No FH & TOTAL & Sensitivity(\%) & Specificity (\%) & PPV (\%) & NPV (\%) & Efficiency (\%) & $p^{-v a l u e}{ }^{\dagger}$ \\
\hline & \multicolumn{9}{|c|}{ Simon Broome } \\
\hline Positive FH & 212 & 4 & 216 & 51.1 & 98.8 & 98.1 & 62.3 & 28.6 & $<0.001^{*}$ \\
\hline Negative FH & 203 & 336 & 539 & & & & & & \\
\hline \multirow[t]{2}{*}{ TOTAL } & 415 & 340 & 755 & & & & & & \\
\hline & \multicolumn{9}{|c|}{ US MEDPED } \\
\hline Positive FH & 105 & 2 & 107 & 25.3 & 99.4 & 98.1 & 56.1 & 14.1 & $<0.001^{*}$ \\
\hline Negative FH & 310 & 338 & 648 & & & & & & \\
\hline \multirow[t]{2}{*}{ TOTAL } & 415 & 340 & 755 & & & & & & \\
\hline & \multicolumn{9}{|l|}{ JFHMC } \\
\hline Positive FH & 195 & 4 & 199 & 47.0 & 98.8 & 97.9 & 60.4 & 26.4 & $<0.001^{*}$ \\
\hline Negative FH & 220 & 336 & 556 & & & & & & \\
\hline TOTAL & 415 & 340 & 755 & & & & & & \\
\hline
\end{tabular}

Significant $={ }^{*} p<0.05 ; \mathrm{FH}=$ Familial Hypercholesterolaemia; DLCC = Dutch Lipid Clinic Criteria; SB = Simon Broome's Register Criteria; USMEDPED = US Make Early Diagnosis to Prevent Early Deaths criteria; JFHMC = Japanese Familial Hypercholesterolaemia Management Criteria; PPV: positive predictive value, NPV: Negative Predictive Value. ${ }^{\dagger}$ Pearson correlation

US MEDPED or the JFHMC (212 vs. 105 vs. 195 respectively, $p<0.001)$. The SB criteria, US MEDPED and JFHMC identified similar number of negative $\mathrm{FH}$ cases in comparison to the DLCC (336 vs. 338 vs. 336 respectively, $\mathrm{p}<0.001)$.

The percentage of subgroups for positive $\mathrm{FH}$ as defined by the SB Register criteria, the US MEDPED and the JFHMC against the subgroups as defined by the DLCC criteria is shown in Table 7. Among the definite FH classified by the DLCC criteria, there were $95.4 \%$ cases defined as definite $\mathrm{FH}$ by the SB Register criteria, 95.4\% as heterozygous $\mathrm{FH}$ by the JFHMC and $50.8 \%$ as heterozygous FH by the US MEDPED criteria. Meanwhile among the unlikely $\mathrm{FH}$ as defined by the DLCC, there were $98.8 \%$ cases defined as "no $\mathrm{FH}^{\text {" by the } \mathrm{SB}}$ Register criteria, 99.4\% as "no FH" by the US MEDPED and $98.8 \%$ as "no FH" by the JFHMC. Furthermore, among the possible $\mathrm{FH}$ by the DLCC, $79.2 \%$ were classified as "no FH" by the SB Register criteria, 92.5\% as "no FH" by the US MEDPED and $84.6 \%$ as "no FH" by the JFHMC. Among the probable $\mathrm{FH}$ as defined by the DLCC, $53.3 \%$ were classified as definite $\mathrm{FH}$ by the SB Register criteria, $46.7 \%$ as heterozygous $\mathrm{FH}$ by the US MEDPED and $71.1 \%$ as heterozygous FH by the JFHMC.

Table 8 shows the association of classifications of subjects with no $\mathrm{FH}$ by the SB Register criteria, US MEDPED and JFHMC with subgroups as defined by the DLCC. Among the No FH by the SB Register criteria, $5.7 \%$ were definite $\mathrm{FH}, 30.9 \%$ were possible $\mathrm{FH}$ while $19.6 \%$ were probable FH by the DLCC. Among, the No FH by the US MEDPED, 91.4\% were definite FH, 36.1\% were possible $\mathrm{FH}$ and $52.2 \%$ were probable $\mathrm{FH}$ by the
DLCC. Similarly, among the No FH by the JFHMC, $5.7 \%$ were definite $\mathrm{FH}, 33 \%$ were possible $\mathrm{FH}$ and $28.3 \%$ were probable $\mathrm{FH}$ by the DLCC. These associations between classifications of subjects with no FH by the SB Register, US MEDPED and JFHMC with subgroups as defined by the DLCC criteria were significant $(p<0.001)$.

\section{Discussion}

At present, there have been various $\mathrm{FH}$ clinical criteria available for various populations but there is scarcity of known gold standard criteria to diagnose FH. To the best of our knowledge, this is the first study to demonstrate the ability of various clinical criteria to identify positive $\mathrm{FH}$ cases in an Asian population. We applied the DLCC as the reference diagnostic criteria to identify index cases because it is largely used in our clinical settings; its similarities to the SB Register criteria and its ability to predict presence of genetic mutations despite a weak phenotype-genotype concordance, [19]. Moreover, it uses lower cut of level for LDL-c with additional indicators such as arcus cornealis, peripheral vascular disease and premature cerebral disease when compared to other criteria, in which potentially greater $\mathrm{FH}$ cases will be identified.

In low-middle income Asian countries, routine genetic testing is technically demanding and costly. Similarly, genetic mutation confirmation parameter was not done for our study due to the financial constraint, which is commonly observed practice in Malaysia. Elucidating diagnostic performances of various clinical $\mathrm{FH}$ criteria, without the use of genetic testing is particularly useful for Malaysia and other Asian populations. Factors such 
Table 7 Percentage of subgroups for positive FH as defined by the SB, US MEDPED and JFHC against the subgroups for positive FH as defined by the DLCC definition

\begin{tabular}{|c|c|c|c|c|c|}
\hline \multirow[t]{2}{*}{ Definitions } & \multicolumn{5}{|l|}{ DLCC } \\
\hline & Definite FH N = $130(\%)$ & Probable FH N = 45 (\%) & Possible FHN = $240(\%)$ & Unlikely FH N = 340 (\%) & $p$-value \\
\hline \multicolumn{6}{|l|}{ Simon Broome } \\
\hline Definite FH & $124(95.4)$ & $24(53.3)$ & $0(0)$ & 0 & $<0.001^{*}$ \\
\hline Possible FH & $2(1.5)$ & $12(26.7)$ & $50(20.8)$ & $4(1.2)$ & \\
\hline No FH & $4(3.0)$ & $9(0.2)$ & $190(79.2)$ & $336(98.8)$ & \\
\hline Total & 130 & 45 & 240 & 340 & 755 \\
\hline \multicolumn{6}{|l|}{ US MEDPED } \\
\hline Heterozygous & $66(50.8)$ & $21(46.7)$ & $18(7.5)$ & $2(0.6)$ & $<0.001^{*}$ \\
\hline No FH & $64(49.2)$ & $24(53.3)$ & $222(92.5)$ & $338(99.4)$ & \\
\hline Total & 130 & 45 & 240 & 340 & 755 \\
\hline \multicolumn{6}{|l|}{ JFHC } \\
\hline Heterozygous & $124(95.4)$ & $32(71.1)$ & $37(15.4)$ & $4(1.2)$ & $<0.001^{*}$ \\
\hline Homozygous & $2(1.5)$ & 0 & 0 & 0 & \\
\hline No FH & $4(3.1)$ & $13(28.9)$ & $203(84.6)$ & $336(98.8)$ & \\
\hline Total & 130 & 45 & 240 & 340 & 755 \\
\hline
\end{tabular}

Significant $={ }^{*} \mathrm{p}<0.05 ; \mathrm{FH}=$ Familial Hypercholesterolaemia; DLCC = Dutch Lipid Clinic Criteria; SB = Simon Broome's Register Criteria; USMEDPED = US Make Early Diagnosis to Prevent Early Deaths criteria; JFHMC = Japanese Familial Hypercholesterolaemia Management Criteria. ${ }^{+}$Pearson correlation

as family or personal history of tendon xanthoma and LDL-c was found to be strongly associated with positive genetic diagnosis in a Spanish population, in which a thorough examination for tendon xanthoma in suspected $\mathrm{FH}$ patients were recommended prior genetic testing [14]. A recent study analyzing 5050 subjects from a UK database recommended an assessment tool algorithm in order to improve the detection of $\mathrm{FH}$ in primary care setting prior to referral for genetic testing [20]. The JFHMC is the only established FH diagnostic criteria for use in the Japanese population and genetic testing is not used to diagnose FH but without validation in other Asian population.

This study found that the SB Register criteria identified more individuals with $\mathrm{FH}$ compared to the US MEDPED and the JFHMC when assessed against the DLCC. All of the criteria had a high specificity but low sensitivity values. Nevertheless, the SB Register criteria had the highest sensitivity compared to the US MEDPED and the JFHMC (51.1\% vs. $25.3 \%$ vs. $47.0 \%$; $p<0.001)$. The low sensitivity or the poor performance in finding the true positive of $\mathrm{FH}$ cases according to the DLCC by the SB Register criteria could be explained by the difficulty of getting a complex family history in order to fulfill the diagnosis of positive FH. Similarly, the US MEDPED and the JFHMC require information on family history of premature CAD and relative's serum cholesterol values to be classified as positive FH. Hence, complex clinical history may deter the performance of these criteria in detecting $\mathrm{FH}$.

Our study found a high positive predictive $(98.1 \%$ vs. 98.1\% vs. $97.9 \%$ ) but lower negative predictive values (62.3\% vs. $56.1 \%$ vs. $60.4 \%)$ by the SB Register criteria, the US MEDPED and the JFHMC respectively. This could be explained by the fact that most of the subjects were identified from tertiary and lipid specialist care, in which prevalence of $\mathrm{FH}$ is higher than the general population. Therefore, the interpretation of the reliability of each criteria to predict true positive $\mathrm{FH}$ and true negative $\mathrm{FH}$ must be done with caution.

Table 8 Association of No FH by the SB Register, USMEDPED and JFHMC with subgroups as defined by the DLCC

\begin{tabular}{lllll}
\hline & \multicolumn{1}{l}{ DLCC } & & & \\
\cline { 2 - 5 } & Definite FH n (\%) & Probable FH n (\%) & Possible FH n (\%) & Unlikely FH n (\%) $^{\mathrm{p} \text {-value }}$ \\
\hline No FH by SB Register & $4(5.7)$ & $9(19.6)$ & $190(30.9)$ & $336(33.3)$ \\
No FH by USMEDPED & $64(91.4)$ & $24(52.2)$ & $222(36.1)$ & $338(33.5)$ \\
No FH by JFHMC & $4(5.7)$ & $13(28.3)$ & $203(33.0)$ & $336(33.3)$ \\
Total & 70 & 46 & 615 & 1010 \\
\hline
\end{tabular}

Significant $={ }^{*} \mathrm{p}<$ 0.05; FH = Familial Hypercholesterolaemia; DLCC = Dutch Lipid Clinic Criteria; SB = Simon Broome's Register Criteria; USMEDPED = US Make Early Diagnosis to Prevent Early Deaths criteria; JFHMC = Japanese Familial Hypercholesterolaemia Management Criteria. ${ }^{\dagger}$ Pearson correlation 
Although the US MEDPED is a simple diagnostic criterion, it was found to be successful in diagnosing only $25.3 \%$ of those diagnosed with $\mathrm{FH}$ when compared against the DLCC. It had the lowest sensitivity and efficiency value compared to other criteria. Furthermore, the majority of its No FH cases were reclassified as definite FH by the DLCC. The JFHMC had better sensitivity, specificity and efficiency value compared to the US MEDPED. The low diagnostic efficiency values in all of the criteria against the DLCC suggests that the SB Register, the US MEDPED and the JFHMC could not identify positive and negative $\mathrm{FH}$ accurately when compared to the DLCC. Future studies comparing these various criteria against results of genetic testing are required to strengthen the recommendation for genetic testing to confirm FH cases detected clinically.

To date, an excess of over 1000 genetic variants have been identified in the Low Density Lipoprotein-Receptor gene (LDLR), Apolipoprotein B-100 gene (APOB), or Proprotein Convertase Subtilisin/Kexin type 9 gene (PCSK9) [21]. Molecular diagnosis is often difficult except in populations where only a limited number of mutations predominate. We postulate that genetic testing would post a challenge in finding true $\mathrm{FH}$ cases due to the presence of vast spectrum of genetic variants in the multiethnic heterogenous population of Malaysia. Given that genetic testing is costly and not readily accessible in many countries, a need to identify the best phenotype indication to achieve accurate yield is required. This would be useful in determining the gold standard criteria for detecting FH in a Malaysian population.

\section{Conclusion}

Our findings concluded that the SB Register criteria was better at detecting FH followed by the JFHMC and US MEDPED in this Asian population. The SB Register criteria has the highest sensitivity value with a comparably high specificity value when compared to the JFHMC and the US MEDPED. This implies SB Register criteria is more useful in identifying cases suitable for further genetic testing compared to the JFHMC and US MEDPED. Further research looking into a suitable diagnosis criterion with high likelihood of positive genetic findings is required in the Asian population including Malaysia.

\footnotetext{
Abbreviations

BMI: Body mass index; BP: Blood pressure; CA: Corneal arcus; CAD: Coronary artery disease; DBP: Diastolic blood pressure; DLCC: Dutch lipid clinic criteria; DNA: Deoxyribonucleic acid; FH: Familial hypercholesterolaemia; HDL: Highdensity lipoprotein; JFHMC: Japanese Familial Hypercholesterolaemia Management criteria; LDL: Low-density lipoprotein; LDLR: Low-density lipoprotein receptor; NICE: National Institute for Health and Care Excellence; SB: Simon broome; SBP: Systolic blood pressure; SEM: Standard Error of Mean; SPSS: Statistical Program for Social Science Software; TC: Total cholesterol; TG: Triglyceride; US MEDPED: United State make early diagnosis to prevent early deaths; WC: Waist circumference
}

\section{Acknowledgements}

The authors would like to express their appreciation to the staff of Centre for Pathology Diagnostic and Research Laboratories (CPDRL) Faculty of Medicine, Universiti Teknologi MARA for providing their assistance in conducting this study

\section{Availability of data and materials}

Data are kept at the Institute for Pathology, Laboratory and Forensic Medicine (I-PPerForM), Faculty of Medicine, Universiti Teknologi MARA. Data will be shared upon request and it is subjected to the data protection regulations.

\section{Authors' contributions}

SAR wrote the manuscript and were involved in the data collection of the study. RR and Zal performed the statistical analysis and contributed to the critical discussion of the results. AMK, TAR, SM, NMN, Zul, SK, RAG, ARS and AR contributed to the critical revision of the manuscript and were involved in the data collection. HN verified the laboratory results and contributed to the critical revision of the manuscript. HN is the Principal Investigator of this study. She played a major role in the conception and design of the study, contributed to the critical revision of the manuscript and intellectual content, and provided expertise and oversight throughout the process. All authors read and approved the final version.

\section{Funding}

This study was supported with grants from the Ministry of Education Malaysia under the Long Term Research Grant Scheme [600-RMI/LRGS 5/3 (2/2011)-2], awarded to the corresponding author.

\section{Ethics approval and consent to participate}

All subjects provided written, informed consent. Approval from the Universiti Teknologi MARA Board of Ethics Committee was obtained prior to commencement of the study. The ethical approval number is 600-RMI (5/1/6/01).

Consent for publication

Not applicable.

\section{Competing interests}

The authors declare that they have no competing interests.

\section{Publisher's Note}

Springer Nature remains neutral with regard to jurisdictional claims in published maps and institutional affiliations.

\section{Author details}

'Institute for Pathology, Laboratory and Forensic Medicine (I-PPerForM), University Teknologi MARA, 47000 Sungai Buloh, Selangor, Malaysia.

${ }^{2}$ Pathology Discipline, Faculty of Medicine, University Teknologi MARA, 47000 Sungai Buloh, Selangor, Malaysia. ${ }^{3}$ Primary Care Medicine Discipline, Faculty of Medicine, University Teknologi MARA, 68100 Selayang, Selangor, Malaysia. ${ }^{4}$ Cardiology Unit, Faculty of Medicine, University Teknologi MARA, 47000 Sungai Buloh, Selangor, Malaysia. ${ }^{5}$ Population Health and Preventive Medicine Discipline, Faculty of Medicine, University Teknologi MARA, 47000 Sungai Buloh, Selangor, Malaysia. ${ }^{6}$ Endocrinology Disciplines, Faculty of Medicine, Universiti Teknologi MARA (UiTM), 47000 Sungai Buloh, Selangor, Malaysia. ${ }^{7}$ National Heart Institute, No 145 Jalan Tun Razak, 50400 Kuala Lumpur, Malaysia.

Received: 13 December 2016 Accepted: 6 October 2017 Published online: 16 October 2017

References

1. Marks D, Thorogood M, Neil HAW, Humphries SE. A review on the diagnosis, natural history, and treatment of familial hypercholesterolaemia. Atherosclerosis. 2003;168(1):1-14.

2. Brown MS, Goldstein JL. A receptor-mediated pathway for cholesterol homeostasis. Science. 1986;232(4746):34-47.

3. Goldstein JL, Brown MS. The cholesterol quartet. Sci [Internet]. 2001; 292(5520):1310-2.

4. Goldstein JL, Brown MS. The LDL receptor. Arterioscler Thromb Vasc Biol. 2009;29(4):431-8. 
5. Hobbs HH, Russell DW, Brown MS, Goldstein JL. The LDL receptor locus in familial hypercholesterolemia: mutational analysis of a membrane protein. Annu Rev Genet. 1990;24(1):133-70.

6. Steering $\mathrm{S}$, Register B. Mortality in treated heterozygous familial hypercholesterolaemia: implications for clinical management. Scientific steering committee on behalf of the Simon Broome register group. Atherosclerosis. 1999;142(July 1998):105-12.

7. Reiner Z, Catapano AL, De Backer G, Graham I, Taskinen M-R, Wiklund O, et al. ESC/EAS guidelines for the management of dyslipidaemias: the task force for the management of dyslipidaemias of the European Society of Cardiology (ESC) and the European atherosclerosis society (EAS). Eur Heart J. 2011;32(14):1769-818.

8. Nordestgaard BG, Chapman MJ, Humphries SE, Ginsberg HN, Masana L, Descamps OS, et al. Familial hypercholesterolaemia is underdiagnosed and undertreated in the general population: guidance for clinicians to prevent coronary heart disease: consensus statement of the European atherosclerosis society. Eur Heart J. 2013;34(45):3478-90.

9. Schaefer EJ, Lamon-Fava S, Jenner JL, McNamara JR, Ordovas JM, Davis CE, et al. Lipoprotein(a) levels and risk of coronary heart disease in men. The lipid research clinics coronary primary prevention trial. JAMA. 1994; 271(0098-7484 (Print)):999-1003.

10. The Long-Term Intervention with Pravastatin in Ischaemic Disease (LIPID) Study Group. Prevention of cardiovascular events and death with pravastatin in patients with coronary heart disease and a broad range of initial cholesterol levels. N Engl J Med. 1998;339:1349-57.

11. LaRosa JC, He J, Vupputuri S. Effect of statins on risk of coronary disease: a meta-analysis of randomized controlled trials. JAMA. 1999;282(24):2340-6.

12. Neil HA, Hammond T, Huxley R, Matthews DR, Humphries SE. Extent of underdiagnosis of familial hypercholesterolaemia in routine practice: prospective registry study. BMJ. 2000;321(7254):148.

13. O'Brien EC, Roe MT, Fraulo ES, Peterson ED, Ballantyne CM, Genest J, et al. Rationale and design of the familial hypercholesterolemia foundation cascade screening for awareness and detection of familial hypercholesterolemia registry. Am Heart J. 2014 Mar [cited 2015 Dec 15]; 167(3):342-9.e17.

14. Civeira F, Ros E, Jarauta E, Plana N, Zambon D, Puzo J, et al. Comparison of genetic versus clinical diagnosis in familial hypercholesterolemia. Am J Cardiol. 2008;102(9):1187-93. 1193.e1

15. Daniel W. Biostatistics: A Foundation for Analysis in the Health Sciences (10th edition). Vol. 30, Technometrics. 1999. 200-203 p.

16. Harada-Shiba M, Arai H, Oikawa S, Ohta T, Okada T, Okamura T, et al. Guidelines for the Management of Familial Hypercholesterolemia. J Atheroscler Thromb. 2012;19(12):1043-60.

17. KDIGO. 2012 clinical practice guideline for the evaluation and Management of Chronic Kidney Disease. Kidney Int Suppl. 2013;3(1):4-4.

18. Ellis KL, Pang J, Chan DC, Hooper AJ, Bell DA, Burnett JR, et al. Familial combined hyperlipidemia and hyperlipoprotein(a) as phenotypic mimics of familial hypercholesterolemia: frequencies, associations and predictions. J Clin Lipidol. 2016;10(6):1329-37. e3

19. Damgaard D, Larsen ML, Nissen PH, Jensen JM, Jensen HK, Soerensen VR, et al. The relationship of molecular genetic to clinical diagnosis of familial hypercholesterolemia in a Danish population. Atherosclerosis. 2005;180:155-60.

20. Weng SF, Kai J, Andrew Neil H, Humphries SE, Qureshi N. Improving identification of familial hypercholesterolaemia in primary care: derivation and validation of the familial hypercholesterolaemia case ascertainment tool (FAMCAT). Atherosclerosis. 2015;238(2):336-43.

21. Rader DJ, Cohen J. Hobbs HH. Monogenic hypercholesterolemia : new insights in pathogenesis and treatment. 2003;111(12):1795-803.

\section{Submit your next manuscript to BioMed Central and we will help you at every step:}

- We accept pre-submission inquiries

- Our selector tool helps you to find the most relevant journal

- We provide round the clock customer support

- Convenient online submission

- Thorough peer review

- Inclusion in PubMed and all major indexing services

- Maximum visibility for your research

Submit your manuscript at www.biomedcentral.com/submit
) Biomed Central 